\title{
Development and Implementation of Suicide Prevention Activities - Report from Slovenia
}

\author{
Saška Roškar1, Alenka Tančič Grum² and Vita Poštuvan ${ }^{3}$ \\ ${ }^{1}$ National Institute of Public Health \\ ${ }^{2}$ University of Primorska, Andrej Marušič Institute \\ Slovenia
}

\section{Introduction}

On-going development and sustainable implementation of suicide prevention activities seem to be important factors that contribute to lower suicide rates over several years. In Slovenia, new programmes, initiatives and suicide prevention and research centres have emerged in the last decades. In our chapter we are presenting very well accepted project Let's Talk about Suicide and its impact on the society. The project is aimed to decrease suicidal behaviour among different high-risk groups. It integrates research, prevention and intervention through different activities targeting healthcare professionals, school counsellors and media.

\section{Background}

\subsection{Suicide - a global public health problem}

In 1984 the WHO's European Member States defined the reduction of suicide as one of their main health policy targets (WHO, 2002). Namely, every year more than 58,000 persons commit suicide/die by suicide within the European Union which is the highest rate for completed suicide in the world (WHO, 2003). Outside European Union the statistic is also devastating as almost 900,000 lives annually are lost worldwide through suicide, representing $1.5 \%$ of the global burden of disease (WHO, 2003). Closely related to completed suicide are non-fatal suicidal acts and their rate can be estimated to be even 10 times higher than that of completed ones. Given these facts, focusing on suicide, its prevention and appropriate interventions should be one of the key public mental health concerns.

\subsection{Prevention/intervention programmes aimed at suicide reduction}

In the past, many intervention programmes aimed at reducing suicide rates were launched, some of which proved more effective than others. In a simple way they can be divided into local (regional) and global (national, international level) prevention programmes of suicide (Marušič, 2008). 
On the local level one of the most successful interventions to prevent suicide (which initially became global as it grew internationally) was the German Nuremberg Project/Nuremberg Alliance against Depression (NAD), which evolved into European Alliance against Depression (EAAD) (Hegerl and Schafer, 2007). Even though the EAAD was not directly aiming at reducing suicide (as it was focusing on depression) the project has had huge success in recognising and treatment of depression (and subsequently suicidality) and can without any doubt be regarded as an example of good practice (efficacy in terms of reduction in suicide and deliberate self-harm was not systematically investigated in EAAD, as was the case in NAD).

On the other hand, in addition to the EAAD approach, some European countries have also developed systematic national suicide prevention strategies. Regular evaluations and monitoring of progress of these strategies is a condition sine qua non as suicidologists need to be aware of what is working and what is not. Furthermore, policy makers must be provided with up to date and applicable data easy to translate into practice (Marušič, 2008).

The state of the art literature reveals that there are many papers listing appropriate divisions of suicide prevention activities. One of the most echoing systematic review on suicide prevention strategies is probably that of Mann and colleagues (Mann et al., 2005) where interventions for suicide preventions are divided in five broader areas:

1. interventions aimed at education and raising awareness among workers in primary health care, broader public and other gate keepers,

2. continuous care for persons and vulnerable groups at high risk,

3. treatment and rehabilitation of persons with mental health illnesses, with particular attention to suicidal risk,

4. restriction of lethal means and

5. guidelines for media on how to-report about suicides.

Recently, Cornelis van der Feltz and colleagues (2011) have conducted a systematic review of suicide prevention activities and have clustered intervention levels of suicide prevention into four groups:

1. focusing on primary health care workers,

2. focusing on general public and gatekeepers,

3. focusing on high-risk groups, and

4. focusing on restricting access to means of suicide.

As we can see, different resources suggest similar prevention and/or intervention activities for dealing with the issue of suicide. Further work on evaluating different kinds of suicide prevention is needed (Feltz-Cornelis et al., 2011; Mann et al., 2005) but we can classify suicide prevention activities into four groups (see Figure 1).

First intervention level is aimed at early recognition of depression and suicide risk in patients on the primary health care level, usually by their general practitioners. Second intervention level aims at raising awareness among the general public about suicide risk factors, signs of suicidality, underlying causes of suicidal behaviour and different forms of help. This level also focuses on gatekeepers training (individuals who have regular contact with suicide high risk groups and can potentially recognise the signs of mental health problems and suicidality, i.e. school counsellors, social workers, psychologists etc; 


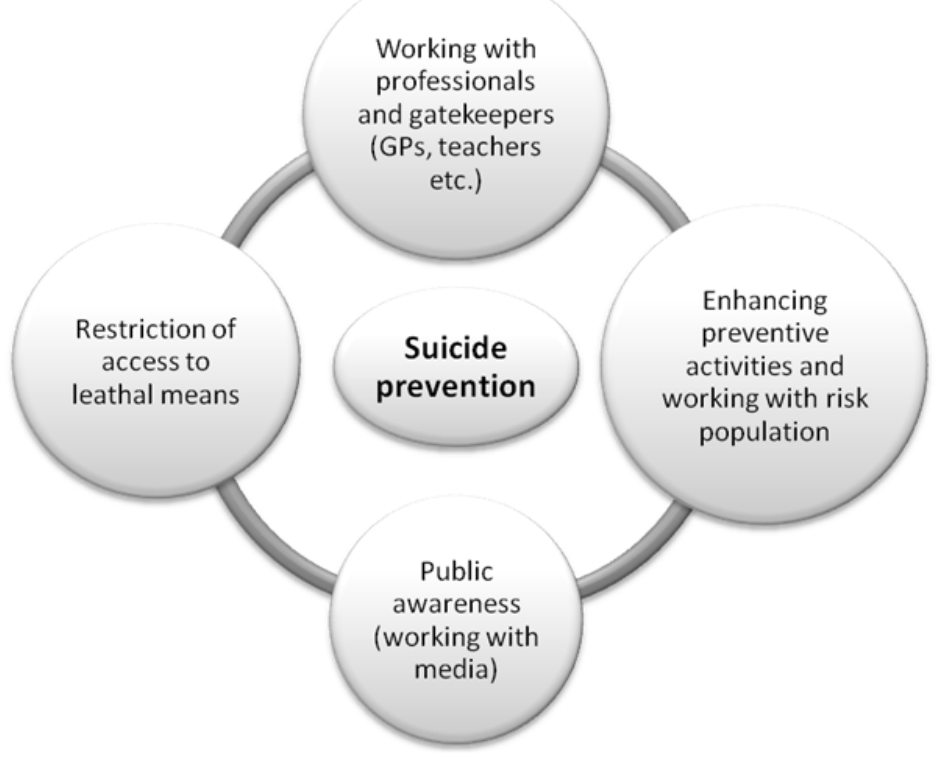

Fig. 1. Core elements of suicide prevention.

Rickwood et al., 2007). Third level of intervention aims at working with high-risk groups. Last but not least, forth level aims at restricting access to lethal means for suicide.

In addition, similar division of suicide prevention activities are listed in WHO strategy (2011b):

1. support and treatment of populations at risk,

2. reduction of availability of and access to means of suicide,

3. establishing and maintaining networks for survivors of suicide, and

4. trainings of primary health care workers and other sectors.

Regardless of different classification of suicide prevention strategies, the authors agree about that not all of listed intervention levels are equally effective in suicide prevention. In fact, rather than focusing on only one intervention level it turns out that focusing multi-level approach is the best way to efficient suicide prevention.

\subsection{Suicide - a major public health problem in Slovenia}

As stressed in the beginning of the chapter, suicide accounts for a great percentage of premature mortality in many European countries. However, suicide rates in Europe vary widely. They are higher in the northern and eastern part of Europe while southern European countries report lower suicide rates (Marušič, 1999). One European country which has traditionally been regarded as a high suicide rate country is Slovenia. With a population of something over 2 million, the average suicide rate for the whole population in Slovenia was 31 per 100000 in the years 1985 - 1994, remaining more or less stable over the years 
(Marušič, 1999). Speaking in absolute numbers this meant approximately 600 lives lost every year due to suicide. The overall male suicide rate for the period 1985 - 1994 was 48.5 and 14.4, for women, resulting in a male to female suicide ratio of about 3.4:1 (Marušič, 1999; National Mortality Database).

Some features of Slovenian suicide resemble suicide characteristics in other countries while others are unique for Slovenia. One such characteristic worthwhile mentioning is the regional distribution of suicides in Slovenia. As previously found by Marušič (1998), the distribution pattern of suicide rates in Slovenia resembles to that in Europe - i.e. suicide rates are highest in the north-eastern part of Slovenia and gradually decrease towards the south-east (Marušič, 1998). Differences in suicide rate between different regions in Slovenia are in some cases as high as are differences in suicide rate between different European countries. Also unique for Slovenia is the fact that hanging is used by majority of suicide victims, namely by two thirds of men and half of women. Usually hanging is a typical suicide method for men, who choose more violent methods (gases, firearms, hanging), while women more often choose poisoning by solid or liquid substances, drowning and jumping from high places (Marušič, 1999). As far as high risk groups are concerned they are similar as in other countries and include older, male, divorced, widowed and people with no formal education.

\subsubsection{Challenges in suicide prevention activities in Slovenia}

In terms of suicide prevention, Slovenia is up against many challenges, i.e. restriction of access to lethal means, improving the care for persons in suicidal crisis etc. The challenges most often pronounced can roughly be divided in following sections:

- $\quad$ under recognition of depression and suicide risk on the primary health care level,

- $\quad$ suicide in the elderly and suicidal behaviour in youngsters,

- the fact, that the subject of suicide is presented as a taboo and as something that is deeply embedded within the Slovenian nationality or national character.

In Slovenia, primary care physicians have a gatekeeping role as it is they who refer a patient to a specialist if needed, i.e. if a mental disorder is diagnosed which requires treatment from a specialist. A study conducted by Rodi et al. (2010) on a Slovenian sample of primary health care patients showed that 30 out of 77 suicide victims visited their primary health care physician in the last month before suicide (16/77 in the last week) whereas only 16 out of 77 controls did so before the index day (3/77 in the last week). In $30 \%$ of suicide victims, the reason for the last visit was mental health problems, while this was the case in only $3 \%$ in the control group. It remains to be investigated in how many cases the primary care physician was able to recognize mental health problems and potential sucidality. Given the fact, that many suicide victims seeks help from their GP prior to suicide speaks in favour of the statement that GP's are the first in the line of suicide prevention. Hence they need proper support in terms of identification of mental health disorders related to suicidality and suicide risk sign. Mental health disorder most often related to suicidal behaviour is depression. A better recognition of depression could thus subsequently lead to a reduction of suicide (as shown in the EAAD study). Roskar et al. (2010) found on a Slovenian sample that education of GP's on depression recognition and treatment of depression resulted in an increase of antidepressant prescription and a tendency of suicide rate drop. 
As reported by Milton and colleagues (1999), the suicide risk is recognized in only $38 \%$ of cases, which is positively related to the presence of a psychiatric diagnosis and negatively with the diagnosis of physical illness. The later poses a particular danger in the elderly population where physical illness is rather a rule than an exception. According to the WHO HFA Database Slovenia is ranking third in the EU in mortality due to suicide in the age group 65 and more. Furthermore, the suicide rate in this age group is much higher than the overall suicide rate (figure 1) (Svetičič, 2010).

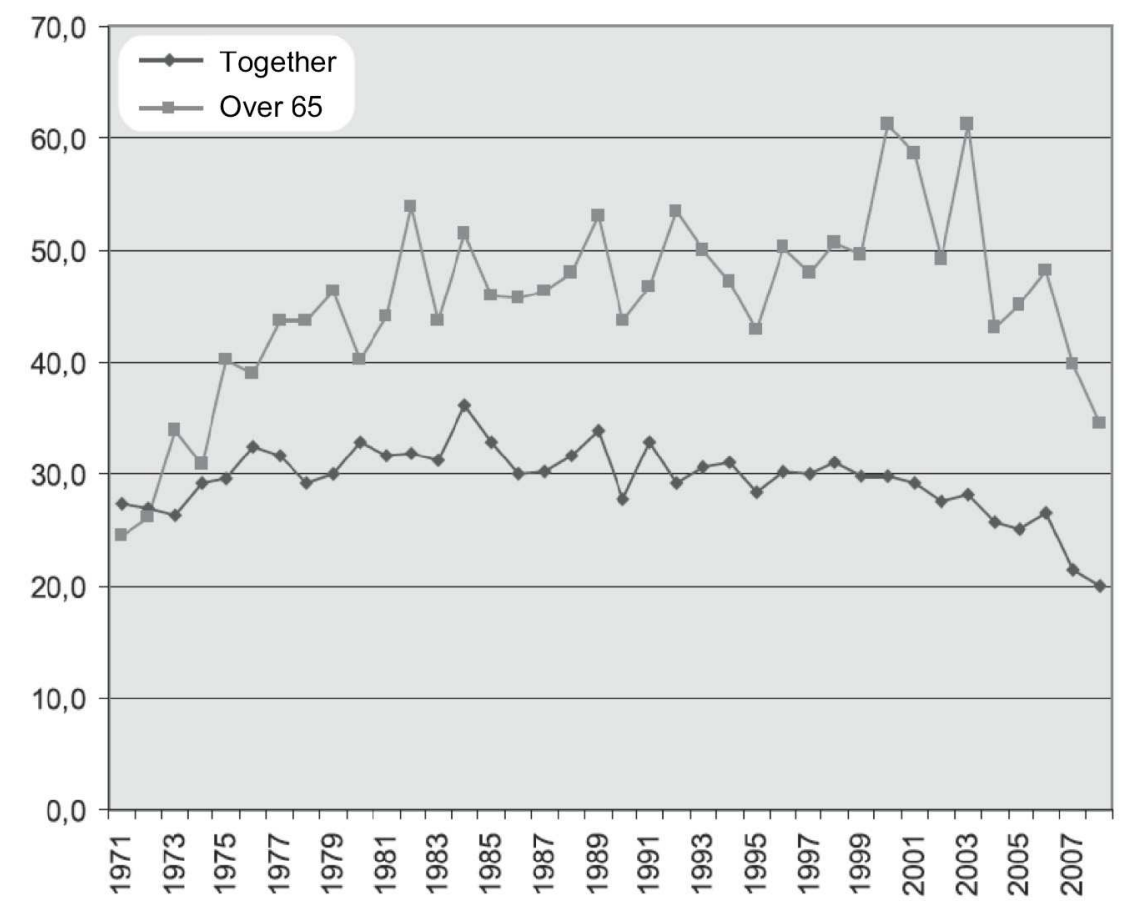

Fig. 2. The overall suicide rate in Slovenia and suicide rate in the age group 65+.

Similarly as in elderly, Slovenia is also above the EU average in terms of suicidality in young people (14-25 yrs) (HFA MDB). What represents a special challenge in this age group is impulsivity of youngsters, under recognition of mental health problems and feelings of low competence to work with a suicidal individual in school workers. Annually, Slovenia loses on average 20 young lives due to suicide.

As stressed many times before, suicide prevention is the task of the society as a whole. If the society acknowledges the problem and is open to speak about it, the stigma is not so pronounced and persons needing help may feel less reluctant to seek help. And vice versa. One of the key gatekeepers in this regard are the media. In Slovenia the reporting on suicide was up until recently marked with sensationalism. The papers reported about all details of suicidal behaviour and showed little or no help possibilities. No guidelines on responsible reporting on suicide were complied. 
The above mentioned difficulties called for action. In the last decade more effort was directed into suicide prevention in Slovenia. The aim of our chapter is to introduce three different suicide prevention activities in Slovenia that were launched in the last years with the aim to tackle challenges of suicidality in Slovenia:

- working with GP's,

- school counsellors and

- the media.

The goal of the first two programmes was to facilitate a better recognition and treatment of suicidal behaviour and to overcome the problem of under recognition of depression and suicidality, whereas the aim of the work with media representatives was to facilitate responsible reporting on suicide. We will particularly address the development of the prevention activities, process of their implementation and difficulties we confronted. We will elaborate on the possible prevention potential these activities had on the suicide rate in Slovenia.

\section{Suicide prevention programmes}

\subsection{Let's Talk about Suicide among Youth}

\subsubsection{Background and aims}

\section{Reasons for focussing on youth suicide prevention}

Young people are in particularly vulnerable for suicidal behaviour and therefore are widely recognised as a suicide-high risk group (Mann et al, 2005). There are several epidemiological reasons why we consider youth as at risk for suicide. The most important one is that young people are more frequently involved into self-harming behaviours (such as self-cutting) than other age groups. Not only that, epidemiological data also shows that they have also more suicidal attempts than other age groups. Moreover, young people are considered as highrisk group also because of some characteristics of their suicidal behaviour. Young people tend not to seek professional help in cases of distress mainly because of their attitude that as they grow up, they need to know how to deal with their problems by themselves. Often, they are also not seeking any professional help because of stigmatisation or peer pressure (Rickwood, Deane and Wilson, 2007). Besides, young people also have a tendency to commit suicides in a more impulsive nature than adults.

Young people have traditionally had relatively low suicide rate in Slovenia, but the number of suicides among youth is increasing globally, which is even more true for other suicidalor self-harm behaviours (Tančič, 2009).

\section{Reasons for focussing on gatekeepers}

School counsellors have a direct access to young people in Slovenia, as each school is obliged to employ at least one psychologist, pedagogue, social worker or someone in similar profession as school counsellor. They collaborate with teachers and school staff among others also in order to help children with emotional problems (e.g. in distress, having mental disorders etc.). Often they educate teachers about mental health of youth and help them to help students. Besides, school counsellors also have individualised approach to students and can intervene in case of emergency. In this way they represent important 
gatekeepers for young people in detecting their suicidal ideations. They are both the gatekeepers that recognize suicidal behaviour among students and need the confidence to act upon cases, and also the ones that pass their skills and knowledge on to teachers and school staff.

The aims of Let's Talk about Suicide among Youth programme were to:

- educate school counsellors about suicidal and self-harming behaviour among youth,

- provide school counsellors tools for coping with suicidal youth,

- evaluate our activities through the changes in attitudes towards suicide, their competences and opinions before and after the intervention.

\subsubsection{Development of the program}

Let's Talk about Suicide among Youth started in 2008 and was the first in our series SoS. Within the span of two years we have run the pilot, evaluated it and prepared an improved program in line with the feedback from the field. Both, the pilot and the final programme consisted of the:

- Development and publishing of a manual with practical guidelines about working with suicidal youth.

- Development and facilitation of a 1-day educational programme covering the content of the manual for school counsellors.

- Evaluation of the program.

The programme was implemented in cooperation between the Institute of Public Health and Slovenian Centre for Suicide Research.

\subsubsection{The pilot in 2008}

The pilot version of the manual consisted of the following topics:

1. Shadow on the sunny part of Alps (chapter on suicide issues in Slovenia)

2. Do we know our youth? (chapter on characteristics of young people)

3. So young and already suicidal (chapter on suicide and young people)

4. Youngsters' help seeking

5. Suicide prevention in schools

6. Terminology dictionary

Besides the manual, the school counsellors of the Ljubljana region were invited to a 1-day education on the same topic. We evaluated the program with the pre-post changes of attitudes toward suicide, feelings of competence and with qualitative answers.

\section{Attitudes towards suicide}

Permissive attitudes toward suicide (these are attitudes that accept suicide more) usually correlate positively with suicidal behaviour and are therefore considered as one of the predictors for suicidal behaviour. People with lenient attitudes toward suicide more often have their own suicidal behaviour or are exposed to suicidal behaviour of others (for example relatives in family). Permissive attitudes might be considered also as the result of exposure to suicidal behaviour and as an attempt to socially justify this kind of behaviour. 
These goes in line with the research that shows that the societies with higher suicide rates also have more permissive attitudes toward suicide (Kodaka et al., 2010).

Using the attitudes as evaluation tool was aimed to find how school counselling staff felt about suicide and to compare the level of functionality of attitudes. Namely, if the attitudes toward suicide are too permissive, they might be dysfunctional for preventing suicide.

\section{Instruments}

We used the Attitudes toward Suicide Questionnaire (ATTS) for our study. The ATTS was developed as an instrument to measure attitudes toward suicide in the general population (Renberg \& Jacobsson, 2003). A recent review on scales that measure attitudes toward suicide (Kodaka et al., 2010) described it as one of the most widely used and more feasible to use.

When we tested the reliability of the previously suggested structure of ATTS, it was very low. Therefore we performed the principal component analysis by ourselves. We identified four dimensions with relatively good statistics. The content of first two dimensions describes the reason for suicidal behaviour. First one (Illness; $a=0,81$ ) justifies suicidal behaviour in cases of illness and the second one (Isolation; $a=0,54$ ) explains the effect of isolation on people with suicidal tendencies. Third and fourth dimension are more related to stigmatisation. The third one (Impulsivity and revenge; $\mathrm{a}=0,70$ ) talks about the impulsivity and revenge (towards other people) as the reasons of suicidal behaviour. The last one (Ability to prevent; $\mathrm{a}=0,53$ ) describes the preventability of suicidal behaviour and reveals the attitudes toward the determination of suicidal thoughts and to what level the society should intervene when preventing.

Procedure and sample

The 44 school counsellors involved in the education were tested before and three months after the education. The data collection was anonymous and the data was used only in an aggregated way. The data were paper-pencil and computer-based, both of which is very common for this profile of people.

\section{Results and discussion}

The overall average on the first dimension was just a bit lower than 3 that was (on a 5-grade scale) the middle value or the neutral value (where people didn't decide whether they agree or disagree) on the scale. According to this result people do not justify suicide because of illnesses. This didn't change a lot after the workshop. The average on the second dimension was again very neutral. There was also no significant differences between the first and second testing. The average on the third dimension is the lowest among dimensions and suggests that people do not consider suicide as an act of impulsivity of revenge. This lowered a bit after the workshop. Participants agreed the most with the last dimension that suggests that we are able and obliged to prevent suicide.

The results revealed that school counselling staff does not justify suicide in cases of illness, have neutral opinions about how isolation might trigger suicidal behaviour, do not find suicide as an impulsive and revengeful act and most importantly, feel it is possible and also necessary to prevent it. The pre-post changes were not statistically significant but showed that there was a bigger variance in the attitudes after the education. This implies that the concept of attitudes cannot be changed easily, but even non-intensive 1-day workshop 

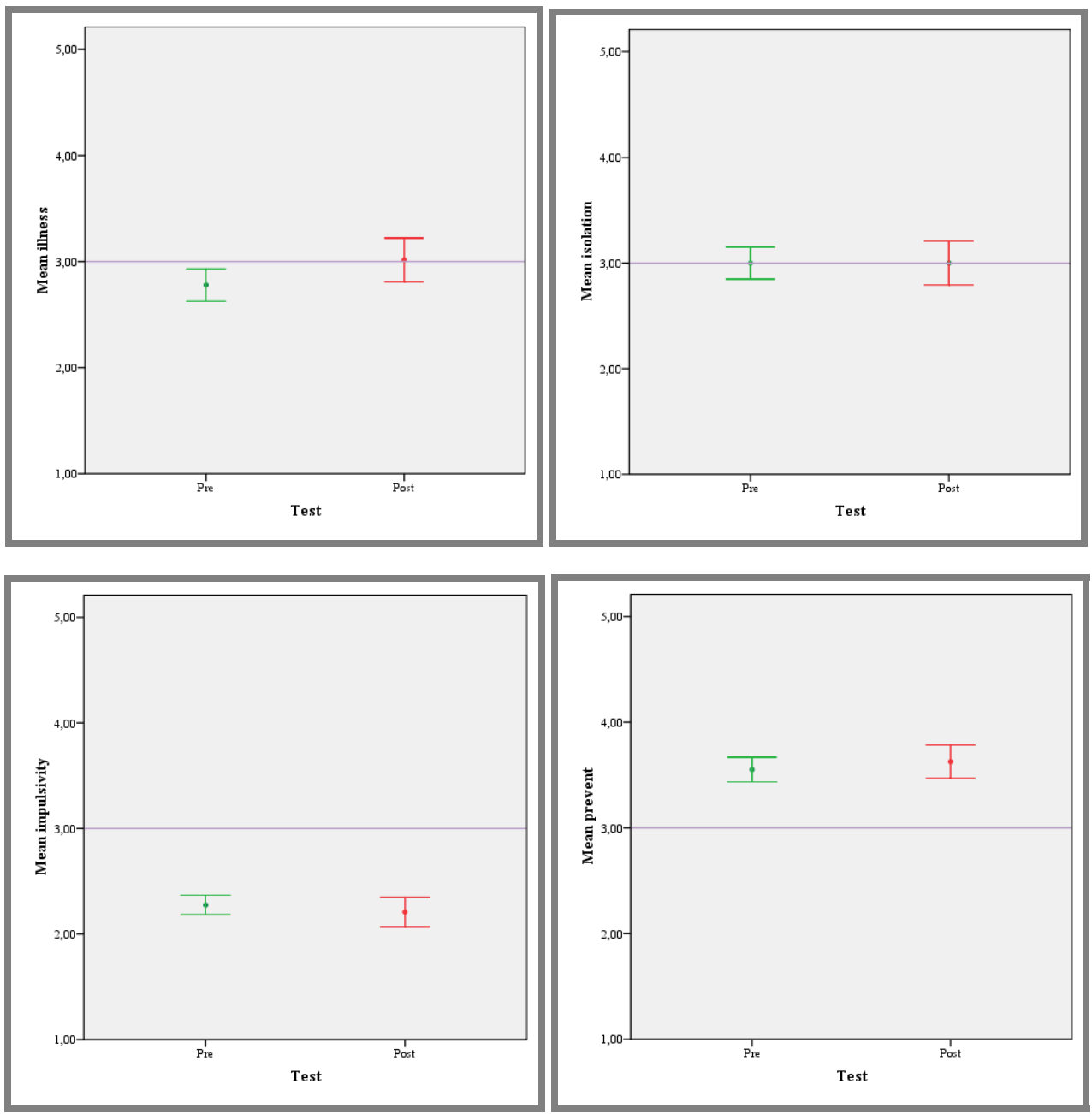

Fig. 3. Pre-post attitudes toward suicide changes.

showed some changes. The bigger variance is important because it shows that the attitudes started to be changed.

\section{Feelings of competence and qualitative answers}

When assessing the feelings of competence, there was a statistically significant improvement of the competence When working with youngsters I recognize signs of suicidal behaviour after the programme. The evaluation of qualitative questions and personal feedbacks at the end of the education revealed high need to address the issues of suicide prevention in the future. The main concern that participant expressed were the lack of concrete information on how to approach a young person in distress and where to refer him/her. 


\subsubsection{The 2009 program}

With the results of the evaluation in mind, we decided to improve our program. We added new chapters to the manual, these were:

- Youngsters in Slovenia about suicide and mental health (the results of a qualitative study of social representations of suicide among youth in Slovenia)

- Where to seek help? (contact points to refer young people)

- From theory to practice (step-by-step advice on dealing with suicidal person, preventive interventions, etc.)

The educational programme was backed up with workshops with very concrete guidelines. Its content was:

1. When to react?

2. How to work with a suicidal youth?

- $\quad$ Mode of questioning

- Mode of listening

- Confidentiality

- Counselling or reference to an expert?

- Suicidal pact

- Cooperation with parents

- Cooperation with youth's peers

- Counsellor's self-care

3. Examples of workshops for prevention on primary level

School counsellors were given a lecture about prevention of suicidal and self-harming behaviour among youth. Moreover they were given an improved manual containing detailed description of all the important facts about suicidal behaviour and about its prevention among youth. This part aimed at expanding their knowledge about suicidal behaviour. Through discussions they could explore their attitudes, beliefs and myths about suicidal behaviour. Workshops gave the opportunity to develop skills through solving problems from real life.

\subsubsection{Implementation and evaluation of the program}

We have used the train the trainer principle to disseminate our knowledge. We had a central training and presentation for regional public health representatives on 10 th September 2009. After that, they have organized regional educations for the school counsellors. Besides, we followed up and made sure that the manual was distributed to every primary or secondary school in Slovenia.

In the second round of the evaluation, the results showed that the programme was well accepted among professionals. The overall evaluation feedback showed very high scores. One of the reviewers of the manual stated: "The authors have prepared a systematic and practical manual, which will be an important educational and supporting tool for school counselling staff and others, who work with youths." Besides, the programme also got positive public response and a lot of media coverage. 


\subsection{Let's Talk about Depression and Suicide among Elderly}

\subsubsection{Background and aims}

According to comparable data on mortality due to suicide in the age group above 65 years, Slovenia ranks among the highest in the world (Svetičič, Marušič \& Kravanja, 2006), as we have already mentioned in the section 2.3.1. Data from the WHO database (HFA Database) shows that the suicide rate for Slovenian elderly is at least two times higher than the total average of all $27 \mathrm{EU}$ member states - between 1985 and 2007 the average in Slovenia was $52 / 100,000$ whereas in the EU the suicide rate was considerably lower $(23 / 100,000)$. In Slovenia, as well as elsewhere in the world, the suicide risk increases with age. The group with the highest suicide risk consists of men over 65 years. Compared with the overall Slovenian population, suicide risk is much higher among the elderly. Suicide rate among the age group above 65 is much higher than Slovenian average - between 1971 and 2008 the suicide risk in that age group was 45 whereas the Slovenian average was as low as 29/100,000 (Grad, Kogoj \& Trontelj, 2001).

Suicidal behaviour among elderly thus presents a serious public health problem in Slovenia. We decided to address the issue with a specific prevention - intervention programme, which we named Let's Talk about Depression and Suicide among Elderly. The field of depression was included in the programme because depression is the most important risk factor for the development of suicidal behaviour in older age (De Leo \& Scocco, 2002).

Also already mentioned in the section 2.3.1, family doctors represent the most important gatekeepers for the identification of depression and suicidal behaviour in the elderly population. Based on the results of foreign studies (Simon et al., 1999; Kohn, Saxena, Levav et al., 2004, Ani, Bazargan, Hindman et al., 2008) which established that more than half of depression cases are not discovered and consequently not treated, we anticipated a similar situation in Slovenia. Therefore we decided a significant portion of the programme should focus on the education of family doctors.

Programme Let's Talk about Depression and Suicide among Elderly started in January 2010 and will conclude in the end of December 2011. The programme was implemented in cooperation between the Institute of Public Health and Slovenian Centre for Suicide Research. As the programme presents a novelty in Slovenia and because it was co-funded by the Municipality of Ljubljana, we wanted to perform a pilot of the programme in the central Slovenian region.

Most important aims of the programme were:

- to increase competence of family doctors of central region of Slovenia in recognition and treatment of depression and suicidal behaviour among elderly patients,

- $\quad$ to support pilot groups of elderly patients with depression in dealing with their illness through psychoeducation.

\subsubsection{Development}

The first 6 months in 2010 were devoted to the developmental phase of the programme. It required the following three steps: 
- Development of a manual with practical guidelines about working with depressed and suicidal elderly patients for family doctors.

- Development of a 1-day pilot educational programme covering the content of the manual for family doctors.

- Development of psychoeducational workshops for elderly patients with depression.

\section{Development of the manual}

Our first activity was focused on developing and publishing a manual with guidelines for recognizing and treating depressed and suicidal elderly patients. The manual was designed for family doctors in primary care setting, but it can be a useful tool for other professionals who work with elderly as well.

Experts who cooperated in the preparation of the manual were: three psychologists from the Institute of Public Health and Slovenian Centre for Suicide Research, a gerontopsychiatrist who leads the Unit for gerontopsychiatry at the Psychiatric Hospital Ljubljana and a family doctor who is a professor at the Medical Faculty and also a researcher in the field of care for elderly.

The manual is divided into two parts. The first part of the manual focuses on the theoretical presentation of the field and consists of six chapters. The first chapter treats older age as a developmental phase and describes its characteristics. The next two chapters present diagnostic criteria for depression and suicidal behaviour according to DSM IV and ICD 10 and the epidemiology of depression and suicide among the elderly in Slovenia and in other states. An extensive chapter is devoted to the risk factors which we divided in four groups: biological (genetic predisposition, physical changes and disease, sleep disorders), psychological (personality characteristics, mental disorders), social (socio-economic status, social support) and others (stress factors, medicine). The first part of the manual also delineates three groups of protective factors: appropriate support resources, effective strategies to cope with stressors and involvement in the activities. The last theoretical chapter is devoted to the characteristics of depression and suicidal behaviour among the elderly. The second part of the handbook represents a practical guide for working with older patients with depression or signs of suicidal behaviour in primary care setting. The first chapter describes general approaches to working with older patients and challenges in dealing with them. In the chapter to follow there are guidelines for screening, diagnosis and treatment of depression and suicidal behaviour in the elderly. Guidelines are also given for referring patients to other specialists. The final chapter sets out proposals for preventive activities that can help older people to maintain good mental health. The manual also includes attachments with important practical value: examples of step-by-step treatment of patients with depression in the outpatient clinic, myths about depression and suicide, together with the explanation, useful contacts for elderly assistance and two screening questionnaires for identifying depression in the elderly - Geriatric Depression Scale and Patient Health Questionnaire 9.

Before publishing the manual, we asked two experts for its review: a family doctor, who is the President of Gerontological Society of Slovenia, and Professor of Medical faculty. 


\section{Development of the educational programme for family doctors}

We wanted to cover the content of the manual in a one-day (8-hour) educational programme, therefore we invited the co-authors of the manual to participate in the development of the programme as well.

In the first part of the educational programme we intended to present the problem of depression and suicidal behaviour among the elderly, focusing on Slovenia. Therefore, we included in it the following topics: the prevalence of depression and suicidal behaviour, the most important risk factors for developing mental disorders and description of the characteristics of depression and suicidal behaviour among older people.

The second part of the educational programme was set on a very practical level. The guidelines for the identification of signs of depression and suicidal behaviour among the elderly and all the steps in the treatment were to be presented through concrete examples from practice and discussion. We also added descriptions on how to approach the older patients, and what the family doctor should be aware of.

The last part of the educational programme was designed in form of a workshop, in which the participants first learn about psychological treatments and options that we have in Slovenia. Then the participants through working in groups try some simple cognitive behavioural techniques that help in coping with depression and suicidal ideation, and contribute to improving mental health.

\section{Development of psychoeducational workshops for elderly patients with depression}

As the Psychiatric Hospital in Ljubljana, already performs workshops for patients with depression and their families, which have proved to be successful, we did not need to develop an entirely new model of workshops. We adapted the existing workshops to elderly population especially in terms of comprehension, so we included simple explanations and anticipated more time for questions. All of the workshop leaders were first trained to conduct the workshops.

A brief description of the workshop (Dernovšek Tavčar, 2005): The workshop consists of four meetings to be conducted once a week. Individual meeting lasts an hour and a half. At the workshop, patients and their relatives receive workbooks, which contain a summary of the programme and tasks aimed at increasing awareness of depression symptoms and how to deal with them. Workshop can be conducted by a graduate nurse, psychologist, physician or other healthcare professional, who concluded the training and is regularly supervised.

Individual parts of the workshop:

1. The first meeting is devoted to identifying factors that influenced the development of depression in an individual. The participants learn about the symptoms and signs of depression.

2. The second meeting focuses on familiarizing the participants with different types of depression treatment, including treatment with antidepressants. Much emphasis is given to the activation of the participants with the support of their relatives. 
3. The third meeting is devoted to the identification of specific thought patterns in depression and to the increase in the flexibility of thinking.

4. The fourth meeting is aimed at the prevention of exacerbations and relapses of depression.

\subsubsection{Implementation}

The implementation phase took place in the second half of 2010 and the first half of 2011 and involved three steps:

- Performing a 1-day educational programme for family doctors in the central region of Slovenia.

- Performing a few psychoeducational workshops for elderly patients with depression.

- Dissemination of the manual to all family doctors in the central region of Slovenia.

In September 2010, in the week the World Suicide Prevention Day took place an educational programme for family doctors was conducted. Through written invitation, through mailing lists and through the publication of the invitation on relevant websites, we invited all of the family doctors from the central Slovenian region to participate in the programme. About a third of the invited, attended the educational programme. The programme was performed by five experts and in accordance with the structure described in the developmental phase. In the scope of the educational programme, a great deal of time was devoted to practical questions of the participants and to discussion. The participants received the manuals and were presented with the other parts of the project. We emphasized the possibility of the psychoeducational workshops for elderly patients and we encouraged the participants to include their patients in the workshops as well.

This was followed by the dissemination of the manuals to all family doctors in the central Slovenian region by mail. When sending the manuals, we encouraged all the family doctors to include their patients in the psychoeducational workshops.

The last part of the implementation phase included conducting the pilot psychoeducational workshops for the elderly with depression and their families, which lasted until the end of June 2011 and was carried out by two psychologists. Four groups, consisting of 15 patients and their relatives were included in this part of the programme. Each psychoeducational workshop was held for four weeks and in accordance with the structure that is described in the developmental phase. At the last meeting the participants were presented with other forms of help which they can use after concluding the workshop.

\subsubsection{Evaluation}

Evaluation phase took place throughout the entire programme; in particular, we focused on the evaluation of three main parts of the programme:

- Manual

- Education for family doctors,

- Psychoeducational workshops for elderly patients with depressive disorder.

We had two important criteria for the evaluation of the manual: the expert opinion of manual containing expert knowledge on depression and suicide among elderly and 
family doctors' and other users' opinion of manual's usefulness in their daily work. As already mentioned, the manual was given in review to the President of Gerontological Society of Slovenia and to Professor of Medical faculty. Manual received positive reviews from both experts; they recommended it for usage to their colleagues - family doctors. Manual evaluation of its applicability in the work of family doctors was obtained through an evaluation questionnaire, which had been completed by every participant at the end of the educational programme. The average score on usefulness of the manual (on 5-level scale) was 4.5 . The same question about usefulness of the manual had been included also in the questionnaire which was sent to all participants 1 year after the educational programme (the questionnaire described below). We are still in the process of collecting and analysing these questionnaires, the evaluation of the manual will be concluded at the end of the year 2011.

For the evaluation of the educational programme for family doctors there were again two criteria: participants' opinion about the educational programme itself and the impact educational programme had on participants' attitudes about depression. Participants' opinions about educational programme were acquired through an evaluation questionnaire that was distributed to all participants at the end of training. The questionnaire included questions about usefulness of content of the educational programme, organization and manual's usefulness, and we asked participants for other comments as well. The average score on usefulness of content of the educational programme was 4.6, on the organisation 4.4 and on the manual 4.5. The impact of educational programme on participants' attitudes about depression we wanted to measure through comparison their attitudes before the educational programme and 1 year after it. For this purpose, all participants completed The Depression Attitude Questionnaire (DAQ) before the lectures of the educational programme started. DAQ (Dowrick et al., 2000) is a self-completion questionnaire which assesses health workers knowledge and attitude towards the causes, consequences and treatment of depression. Each question has four possible responses: strongly disagree, moderately disagree, moderately agree and strongly agree. One year after the educational programme we have again sent one questionnaire to participants. The questionnaire included DAQ, but also questions about the usefulness of the manual and the content of educational programme in their daily work. We do not have the results yet, since we are still in the process of collecting and processing questionnaires - the evaluation concludes at the end of 2011.

Psychoeducational workshops for elderly patients with depressive disorder were evaluated from participants' view and workshop leaders' view. All participants completed an evaluation questionnaire at the end of the last meeting. Through the questionnaire we asked them if the workshop was helpful in their dealing with the depression, how useful was content of the workshop and how they felt in the group. All participants responded that the workshop was of help to them, the average score of usefulness was 4.4, and of their feeling in the group 4 . Since the workshops were conducted as a pilot, we also asked workshop leaders about their suitability. They agreed that the content of the workshop is suitable for wider implementation but as the elderly need more time for understanding the topics, they proposed the extension of the workshop for one meeting. 


\subsection{Let's Talk about Suicide and Media}

\subsubsection{Background and aims}

There is evidence that the media plays a significant role in both suicide risk and suicide prevention. On the one hand, vulnerable individuals may be influenced to engage in imitative behaviours by reports of suicide. Systematic reviews of studies on media impact on suicide risk have consistently drawn the same conclusion: media reporting of suicide can lead to imitative suicidal behaviours (Pirkis, Blood, 2001; Stack, 2000 and 2005 ...). According to these reviews imitation is more evident when the coverage is extensive, prominent, sensationalist and/or explicitly describes the method of suicide. Repeated coverage and 'high impact' stories are being most strongly associated with imitative behaviours (Etzersdorfer, Voracek and Sonneck, 2004), especially when person described in the story and the reader or viewer are similar in some way, or when the person described in the story is a celebrity and is held in high regard by the reader or viewer (Cheng et al., 2007). Specifically vulnerable to engaging in imitative suicidal behaviours are particular subgroups in the population (e.g., young people, people suffering from depression) (Phillips, Carstensen, 1988). The study from Fu and Yip (2007) also showed that imitation of suicide after media reporting varies as a function of time, usually peaking within the first three days and levelling off by about two weeks, but sometimes lasting longer. Along with described characteristics of media reporting, which can influence the imitative suicidal behaviour we have to mention another one - overt description of suicide by a particular method may lead to increases in actual suicidal behaviour employing that method (Hawton et al., 1996).

On the other hand, responsible reporting may serve to educate the public about suicide, and may encourage those at risk of suicide to seek help. There is also some evidence regarding the potential for the media to exert a positive influence, which comes from a study which considered whether 'best practice' media reporting of suicide could lead to a reduction in completed and attempted suicide rates. The study by Etzersdorfer and colleagues (1998) showed that the introduction of media guidelines regarding reporting suicides on the Vienna subway had an important result. There was a reduction in sensationalist reporting of these suicides and, which lead to a $75 \%$ decrease in the rate of subway suicides and a $20 \%$ decrease in the overall suicide rate in Vienna. After that they repeatedly distributed the guidelines nationwide, which resulted in a great success - a trend change in national Austrian suicides. Specially regions with strong media collaboration were more prone to this positive impact in and it is important that the impact was largely maintained over time.

Even though there was no study on media reporting and its impact on suicide conducted in Slovenia, above mentioned studies gave us enough evidence about how media reporting of suicide can lead to imitative behaviours, resulting in statistically significant increases in completed and attempted suicide rates, and on the other hand that responsible reporting can have very positive impact and serve as suicide prevention. And since suicide is such great problem in Slovenia and since noticing the reporting on suicide in Slovene media was marked with sensationalism, with no guidelines on responsible reporting on suicide to rely on, we decided develop a programme Let's Talk about Suicide and Media. 
Most important aim of the programme was:

- To increase awareness of journalists and other media representatives about responsible reporting about suicide and suicidal behaviour in media.

Programme Let's Talk about Suicide and Media started in January 2009 and will conclude in the end of December 2012. The programme was implemented in cooperation between the Institute of Public Health and Slovenian Centre for Suicide Research.

\subsubsection{Development}

The first year of the project was devoted to the development of the programme and guidelines. It consisted from the following steps:

- Translation and adaptation of WHO/IASP guidelines.

- Discussion on the content of guidelines with an expert group of journalists (focus group format).

- $\quad$ Preparation and publication of the final version of guidelines.

- Development of the workshop for journalists and editors.

International Association of Suicide Prevention (IASP) and WHO have published the media guidelines on responsible media reporting in the year 2008. The guidelines were first published in English, but in the following years they have already been translated in several other languages and adapted to different cultures. As IASP members we have gotten the approval from WHO to translate and adapt the guidelines to Slovene language. The initial step of the Let's Talk about Suicide and Media project was therefore the translation of the WHO/IASP guidelines which was done in a consortium of a journalist involved in mental health topics and three psychologists working in the field of suicidology (from the Institute of Public Health and Slovenian Centre for Suicide Research). The outcome was a first draft of the Slovene guidelines on responsible media reporting on suicide.

Afterwards, we wanted to evaluate the draft with our target group (journalists, editors). Therefore, we invited journalists from all major media houses in Slovenia to read the draft and to participate in a focus group. A group of twelve journalists and editors discussed the guidelines content and format with us. The data collected were qualitative responses and opinions about our draft guidelines. The main suggestions on the content from the participants of the focus group were to include some concrete examples for specific guidelines (e.g. what is an appropriate and inappropriate title of the article) and vignettes about how to write an optimal article covering suicide event.

In line with the results, the cultural adaptation of the guidelines was prepared and the final version of the guidelines was published. Besides incorporating the journalists' suggestions (concrete examples and vignettes) we also included other extra chapters in the guidelines:

- Contacts of professionals in field of suicidology.

- Contacts of professional help for people in need (according to guidelines these should be essentially included in any reporting about suicide).

- Most important myths about suicidal behaviour and their explanations.

- Guidelines on how to respond to a call of a suicidal person in a life-broadcasting radio or TV show. 
Final stage of the development of the programme was preparation of the workshops for journalist and editors. The length of the workshop was 2 hours and included presentation of all important guidelines with concrete examples from Slovene media and questions for discussion.

\subsubsection{Implementation}

The implementation began in the September 2010 and is still on going. The parts of the implementation are:

- Dissemination of the manual to all registered journalists in Slovenia.

- Presentations and informative workshops on the content of guidelines for journalists and interested media houses in all the regions of Slovenia.

The beginning of the dissemination of the guidelines was marked with a big national opening ceremony on the World Suicide Prevention Day in 2010, where published guidelines were first time presented to the public. Afterwards we disseminated the guidelines to interested journalists and editors in Slovenia, with the help of Slovene Journalists' Association. Not only that, the guidelines are also available free of change online (webpage of Institute of Public Health).

The presentations and informative workshops on the content of guidelines for journalists and interested media houses were conducted in all nine regions of Slovenia with the help of regional public health representatives. All local and regional journalists from different types of media were invited to participate in the workshops free of charge. Participants represented all main media houses of Slovenia and were from newspapers, online media, radio and television. Among them, there were also a few editors. They all received a paper version of guidelines.

\subsubsection{Evaluation}

The evaluation of the programme consists of:

- $\quad$ pre-post questionnaire on attitudes toward suicide and reporting on suicide

- $\quad$ pre-post qualitative and quantitative analysis of media reporting on suicide.

In the first phase, editors and journalists, who participated at the educational workshops, took part. Before the workshop they filled in a paper version of two questionnaires: Attitudes Toward Suicide Questionnaire (ATTS, Renberg \& Jacobsson, 2003) and a questionnaire on reporting about suicide (the questionnaire was developed by the editors of the guidelines). The post-evaluation will be done in the beginning of year 2012 by sending the same questionnaires to journalists who participated in the workshops.

In the second evaluation phase, we will use qualitative and quantitative analysis of the contents of the reporting of suicide in selected media (particularly newspapers and online media). The number of suicide reports after the education period will be followed up and the content of the report will be analysed. This evaluation will enable us to compare the effect of the implemented guidelines and workshops on the reporting of Slovene media on the subject of suicide. These second evaluation will take place in the second half of the year 2012. 


\section{Conclusion - making progress in suicide prevention activities in Slovenia}

In the last two decades, Slovenia has acknowledged the high prevalence and problem of suicide. The taboo has loosened up a little bit and the topic becomes easier to talk about. Many preventive activities and initiatives arouse, aimed at reducing suicide, raising awareness and aimed at different professionals.

Let's Talk about Suicide programme was one of the initiatives. What is very important about this programme is that it has used the train the trainer approach, by which a broad public was affected. People trained by the facilitators have used this knowledge in their direct work with high risk groups. Besides, they were encouraged to further educate their colleagues and were also the resource of knowledge for them. It was also important that the educational meetings created the opportunity to create networks of people and encourage the exchange of experiences, knowledge and ideas not only from the suicidologists, but also among gatekeepers themselves.

Programmes Let's Talk about Suicide among Youth and Let's Talk about Depression and Suicide among Elderly directly addressed the feelings of competence and self-confidence in dealing with suicidal persons. What seems to be a very useful tool are the manuals, which can help the gatekeepers to refresh their knowledge. All of them were accepted in a very good manner and are also widely used by different lay and professionals all over Slovenia.

We can say from the first impressions from conducting the programme Let's Talk about Suicide and Media that we still need to target journalists in specific fields. It seems that so far the chronicle-section journalists were most eager to join the educational workshop, but not many journalists from sports- or culture-sections participated. This clearly is a lack, as it was seen from the case studies that in cases of suicide of specific sports celebrities, journalists from the sports-sections prepare the articles and they lack the understanding of responsible reporting. So, in this manner, the dissemination of the guidelines needs to be broader. Nonetheless, we have also encountered changes of media reporting, in particular including information of the helplines and other contacts of help for the people in need in numerous articles on the topic of suicide (but only the evaluation phase will give us the more exact results).

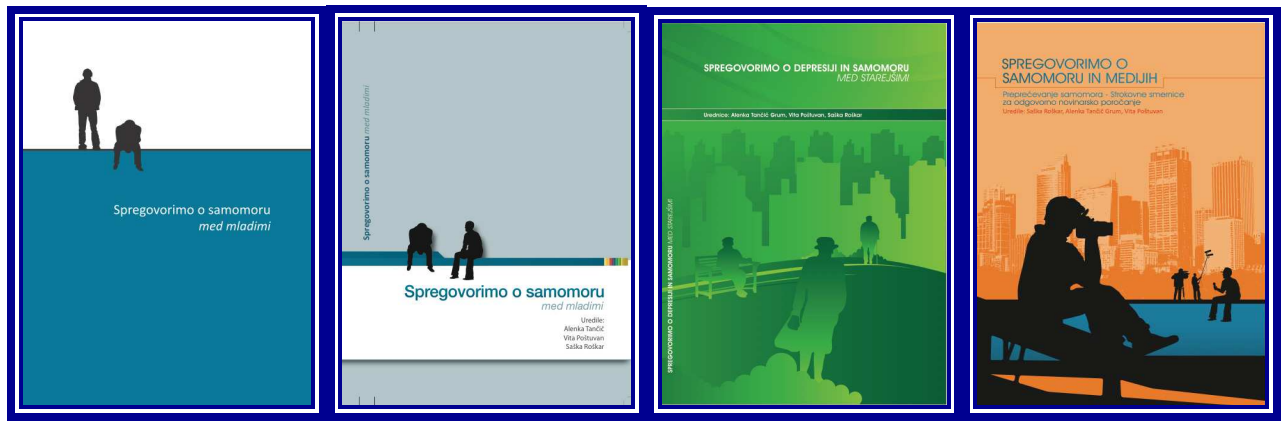

Fig. 4. Front pages of the manuals (first two: Let's Talk about Suicide among Youth, third: Let's Talk about Depression and Suicide among Elderly and last: Let's Talk about Suicide and Media). 
The limitations of the project are at the first in the limited funding. So far, we were not able to provide the sustainability of the educations or to repeat them. We would wish that the topics of suicidal behaviour would become a part of the system (e.g. education of GPs, nurses ...), which is at this moment done only in part. What is more, we have encountered a problem of low response rate in some gatekeepers and in some regions of training. Probably the reason for this is on the one hand still in the lack of awareness about the importance of these topics or on the other hand the lack of time (e.g. for GPs).

Nonetheless, in the last decade (1997 - 2010) we noticed a 14\% decline in the overall suicide rate, $11.4 \%$ decline for men and $19 \%$ decline for women (see figure 5 ). The decline was noticed in all age groups. This probably means that the initiatives that were launched in Slovenia were designed in such a manner that they targeted the before mentioned challenges of suicidality in Slovenia and furthermore followed the guidelines on successful suicide prevention strategies (as outlined by Mann et all, 2005; van der Feltz et al., 2011).

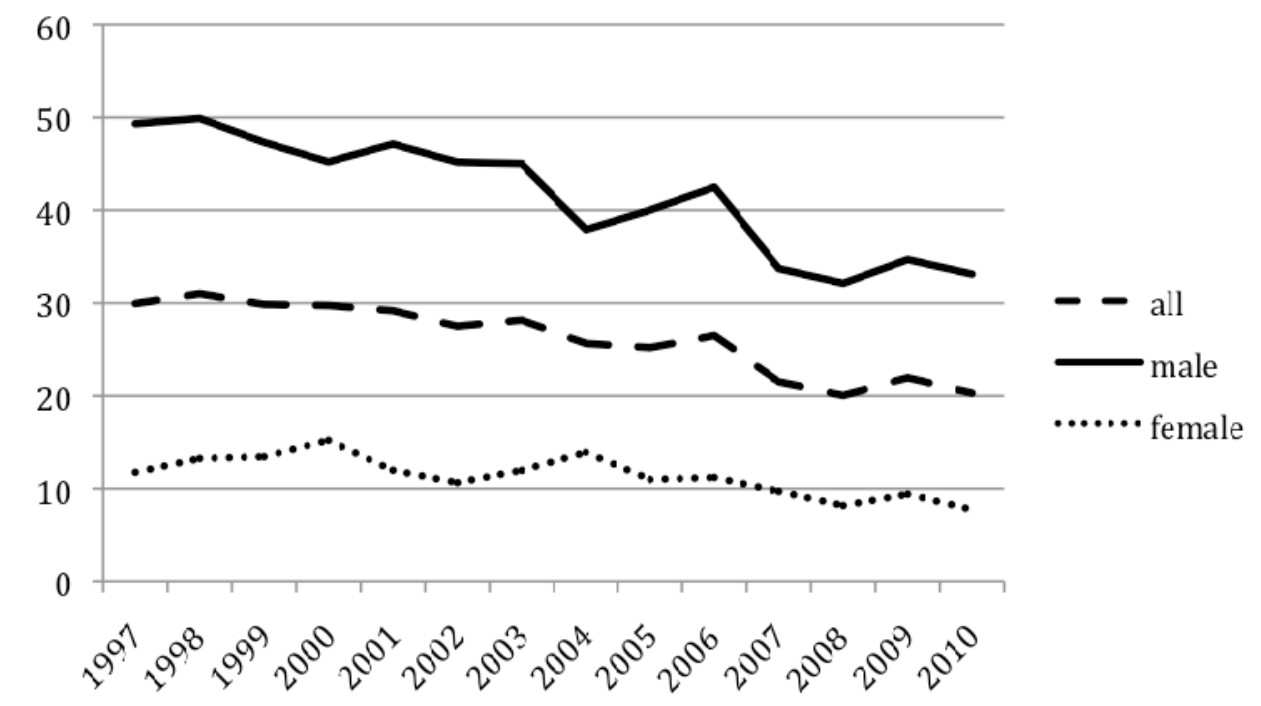

Fig. 5. Suicide rate in Slovenia in the years 1997 - 2007 (National Mortality Database, IVZ).

And that, namely the suicide prevention, is the main goal our programs are trying to achieve.

\section{References}

Ani C, Bazargan M, Hindman D, Bell D, Farooq MA, Akhanjee L et al. (2008). Depression symptomatology and diagnosis: discordance between patients and physicians in primary care settings. BMC Fam Pract; 9:1.

Cheng ATA, Hawton K, Chen THH, Yen AMF, Chang J-C, Chong M-Y, et al. (2007). The influence of media reporting of a celebrity suicide on suicidal behaviour in patients with a history of depressive disorder. Journal of Affective Disorders, 103, pp. 69-75. 
De Leo D, Scocco P. Treatment and Prevention of Suicidal Behaviour in the Elderly. (2002). In: Hawton K. in van Heeringen K, editors. The International Handbook of Suicide and attempted suicide. West Sussex: Willey, pp. 553-570.

Dernovšek MZ, Tavčar R. (2005). Prepoznajmo in premagajmo depresijo: priročnik za osebe z depresijo in njihove svojce. Ljubljana: IVZ RS.

Dowrick, C., Gask, L., Perry, R., Dixon, C. and Usherwood T. (2000). Do general practitioners' attitudes towards depression predict their clinical behaviour? Psychological Medicine, 30, pp. 413-419.

Etzersdorfer E, Sonneck G. (1998). Preventing suicide by influencing massmedia reporting: The Viennese experience 1980-1996. Archives of Suicide Research;4(1), pp. 64-74.

Etzersdorfer E, Voracek M, Sonneck G. (2004). A dose-response relationship between imitational suicides and newspaper distribution. Archives of Suicide Research, 8(2), pp. 137-145.

Fu KW, Yip PSF. (2007). Long-term impact of celebrity suicide on suicidal ideation: Results from a population-based study. Journal of Epidemiology and Community Health, 61(6), pp. 540-546.

Grad TO, Kogoj A, Trontelj J. (2001). Elderly suicide in Slovenia. In: de Leo D, editor. Suicide and euthanasia in older adults: A transcultural journey. Seattle: Hogrefe \& Huber Publishers, pp. $77-88$.

HFA Database. 5th July 2010. Available from: http:/ / www.euro.who.int

Hawton K, Simkin S, Deeks J, O'Connor S, Keen A, Altman DG, et al. (1996). Effects of a drug overdose in a television drama on presentations to hospital for self poisoning: Time series and questionnaire study. British Medical Journal; 318(7189), pp. 972-977.

Hegerl, U. and Schafer, R. (2007). From the Nuremberg Alliance Against Depression to a European network (EAAD) - Extending community-based awareness-campaigns on national and European level. Psychiatrische Praxis, 34, pp. S261-5.

Kodaka, M., Poštuvan, V., Inagaki, M., Yamada, M. (2010). A Systematic Review of Instruments measuring attitudes toward suicide. International Journal of Social Psychiatry, ePub..

Kohn R, Saxena S, Levav I,3 \& Saraceno B. (2004). The treatment gap in mental health care. Bulletin of the World Health Organization, 82, pp. 858-66.

Mann JJ, et al. (2005). Suicide Prevention Strategies. Journal of the American Medical Association, 294 (16), pp. 2064-74.

Marušič A. (1999). Suicide in Slovenia: lesson for cross-cultural psychiatry. International Review of Psychiatry, 11, pp. 212-218.

Marušič A. (1998). Suicide mortality in Slovenia: Regional variation. Crisis, 19, pp. 159-167.

Marušič, A. (2008). Seven steps to Integrating Suicidology. Crisis, 29 (3), pp. 115-117.

Milton, J., Ferguson, B. \& Mills, T. (1999). Risk assesment and suicide prevention in primary care. Crisis, 20(4), pp.171-177.

Phillips DP, Carstensen LL. (1988). The effect of suicide stories on various demographic groups, 1968-1985. Suicide and Life Threatening Behavior;18(1), pp. 100-114.

Pirkis J, Blood RW. (2001). Suicide and the media: (1) Reportage in nonfictional media. Crisis, 22(4), pp. 146-154.

Rickwood, D. J., Deane, F. P., \& Wilson, C. J. (2007). When and how do young people seek professional help for mental health problems? Med J Aust, 187, pp. 35-39. 
Renberg, E.S. \& Jacobsson, L. (2003) Development of a questionnaire on attitudes towards suicide (ATTS) and its application in a Swedish population. Suicide $\mathcal{E}$ LifeThreatening Behavior, 33, 52-64.

Rodi PM, Roskar S, Marusic A. (2010) Suicide Victims Last Contact With the Primary Care Physician: Report From Slovenia, Int J Soc Psychiatry 56, 280.

Roskar S, Podlesek A, Zorko M, Tavcar R, Dernovsek MZ, Groleger U, Mirjanic M, Konec N, Janet E, Marusic A. (2010). Effects of training program on recognition and management of depression and suicide risk evaluation for Slovenian primary-care physicians: follow-up study. Croat Med J., 51 (3), pp. 237-42.

Simon GE, Goldber D, Tiemens BG, Ustun TB. (1999). Outcomes of recognized and unrecognized depression in primary in an international primary care study. Gen Hosp Psych, 21, pp. 97-105.

Stack S. (2000). Media impacts on suicide: A quantitative review of 293 findings. Social Science Quarterly, ;81(4), pp. 957-972.

Stack S. (2005). Suicide in the media: a quantitative review of studies based on non-fictional stories. Suicide and Life Threatening Behavior, 35(2), pp. 121-33.

Svetičič J, Marušič A, Kravanja M. (2006). Slovenija z najvišjim količnikom samomorov med starejšimi na svetu. Zbornik strokovnih prispevkov srečanja: Izobraževalni program iz javnega $z$ dravja IV: socialne determinante zdravja "Zdravo staranje, iluzija ali realnost?". Maribor: ZZV Maribor in IVZ RS,.

Tančič, A. (2009). Tako mlad pa že samomorilen. In Spregovorimo o samomoru med mladimi. Ljubljana: IVZ.

Van der Feltz-Cornelis, C. M., Sarchiapone, M., Postuvan, V., Volker, D., Roskar, S., Tancic Grum, A., Carli, V., McDaid, D., O'Connor, R., Maxwell, M., Ibelshäuser, A., Van Audenhove, C., Scheerder, G., Sisask, M., Gusmão, R., \& Hegerl, U. (2011). Best practice elements of multilevel suicide prevention strategies: A review of systematic reviews. The Journal of Crisis Intervention and Suicide.

WHO. (2002). The World Health Report 2003. Shaping the Future.

WHO. (2003). Suicide prevention in Europe. The WHO European monitoring survey on national suicide prevention programmes and strategies.

WHO (2011b). SUPRE Prevention of suicidal behaviours: a task for all. 29th September 2011. Available on:

http://www.who.int/mental_health/prevention/suicide/information/en/index. html 


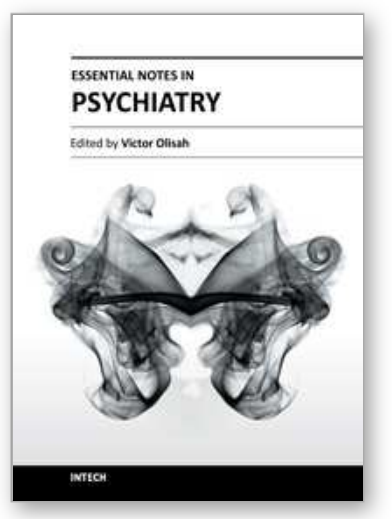

\author{
Essential Notes in Psychiatry \\ Edited by Dr. Victor Olisah
}

ISBN 978-953-51-0574-9

Hard cover, 580 pages

Publisher InTech

Published online 27, April, 2012

Published in print edition April, 2012

Psychiatry is one of the major specialties of medicine, and is concerned with the study and treatment of mental disorders. In recent times the field is growing with the discovery of effective therapies and interventions that alleviate suffering in people with mental disorders. This book of psychiatry is concise and clearly written so that it is usable for doctors in training, students and clinicians dealing with psychiatric illness in everyday practice. The book is a primer for those beginning to learn about emotional disorders and psychosocial consequences of severe physical and psychological trauma; and violence. Emphasis is placed on effective therapies and interventions for selected conditions such as dementia and suicide among others and the consequences of stress in the workplace. The book also highlights important causes of mental disorders in children.

\title{
How to reference
}

In order to correctly reference this scholarly work, feel free to copy and paste the following:

Saška Roškar, Alenka Tančič Grum and Vita Poštuvan (2012). Development and Implementation of Suicide Prevention Activities - Report from Slovenia, Essential Notes in Psychiatry, Dr. Victor Olisah (Ed.), ISBN: 978953-51-0574-9, InTech, Available from: http://www.intechopen.com/books/essential-notes-inpsychiatry/development-and-implementation-of-suicide-prevention-activities-report-from-slovenia

\section{INTECH}

open science | open minds

\section{InTech Europe}

University Campus STeP Ri

Slavka Krautzeka 83/A

51000 Rijeka, Croatia

Phone: +385 (51) 770447

Fax: +385 (51) 686166

www.intechopen.com

\section{InTech China}

Unit 405, Office Block, Hotel Equatorial Shanghai

No.65, Yan An Road (West), Shanghai, 200040, China

中国上海市延安西路65号上海国际贵都大饭店办公楼 405 单元

Phone: +86-21-62489820

Fax: +86-21-62489821 
(C) 2012 The Author(s). Licensee IntechOpen. This is an open access article distributed under the terms of the Creative Commons Attribution 3.0 License, which permits unrestricted use, distribution, and reproduction in any medium, provided the original work is properly cited. 